Note: This is a pre-copy-editing, author-produced PDF of an article accepted for publication in Journal of Substance Use following peer review. The definitive publisher-authenticated version [NicGabhainn S (2003) Assessing sobriety and successful membership of Alcoholics Anonymous, Journal of Substance Use, 8, 55-61] is available online at http://www.informaworld. com/smpp/title content $=\mathrm{t} 713655978$

\title{
Assessing sobriety and successful membership of Alcoholics Anonymous
}

\author{
SAOIRSE NIC GABHAINN \\ National University of Ireland, Galway, Ireland \\ Published in Journal of Substance Use (2003) 8, 55-61 \\ Copyright: Taylor \& Francis
}

\begin{abstract}
Aims This study aimed to identify appropriate measures of successful membership of Alcoholics Anonymous and to investigate membership patterns and perceptions of sobriety across sociodemographic categories of AA membership.

Design This study employs a cross-sectional survey design. All research participants were members of Alcoholics Anonymous based in the community.

Participants Seventy-seven participants from nine individual AA groups returned questionnaires. These compare favourably in relation to age, gender, and length of membership and time since last alcoholic drink with previous samples of AA members.

Measurements All data were collected by means of a self-completion questionnaire which included open-ended questions on respondents' understanding of successful AA membership along with closed questions on meeting attendance, 12-stepping activity and length of membership.

Findings Successful AA membership was associated with sobriety as well as longevity of membership, attendance at AA meetings and commitment to 12-step work. There were few differences across sociodemographic groups in perceived successful membership.

Conclusions Simple measures of success, as suggested by previous authors and volunteered here by AA members themselves, which have the advantage of not illustrating bias according to sociodemographic group can be easily employed in further research with this population.
\end{abstract}

Keywords: Alcoholics Anonymous; process; sobriety

\section{INTRODUCTION}

Alcoholics Anonymous (AA), founded in Ackron, Ohio in 1935 by 'Dr Bob and Bill W.' has been referred to as the 'grandparent' of all self-help groups (Gilbert 1991). It is widely regarded to have been an outgrowth of the Oxford Group Movement in the USA (Clark 1951, Davidson 2002) and the timing of its foundation reflects the drinking patterns of post-First World War and post-Prohibition America (e.g. WW 1949, Alcoholics Anonymous 1976, Chappel 1992). The pragmatism of William James and Jung's concept of religious conversion are also widely acknowledged as precursors of AA (e.g. Kassel and Wagner 1993, Davidson 2002). Little research has been undertaken on the perceptions of AA members of the therapeutic mechanisms underlying membership. This paper examines the experiences of AA members and focuses specifically on their perceptions of sobriety and what it means to be a successful AA member.

Weisner et al. (1995) report that worldwide AA membership has grown in a geometric fashion, from about 100 members in 1940, 476000 in 1980, 653000 in 1983 to 979000 in 1990. More recently, the AA world service website estimates a membership of 2215293 constituted in 100131 groups worldwide (AA 2002). Forms of help-seeking by former 
drinkers in the USA were investigated by Hasin and Grant (1995) who found that about $6 \%$ of former drinkers say that they attended AA and this contributed to a total of $7.5 \%$ who had received any form of help. Similar, but indirect evidence collected from the adult children of problem drinkers in England suggested that of 170 offspring, 50 could recall their parents receiving help from a treatment unit, voluntary agency or self-help group. Twenty-seven (54\%) of the parents had been members of AA but had no formal treatment experience (Velleman and Orford 1990). Clearly, most of those who looked for or received help did so from Alcoholics Anonymous (although not necessarily uniquely so). As Weisner et al. (1995) report, it is rare to find anyone in the formal treatment system that has no prior experience of AA. While treatment experiences have been increasing overall, a disproportionate number have been attending AA and this is particularly the case for women.

Numerous authors have attested to the primacy of the AA model in alcoholism treatment (e.g. Zweben et al. 1987, Emrick 1989, Miller and Mahler 1991, Miller et al.1997). Indeed, 98\% of professionals contacted by Kurtz (1984) agreed that the methods of AA helped their alcoholic clients in the primary goal of maintaining sobriety while $79 \%$ of those contacted by Humphreys (1997) regularly referred clients to AA. A word of warning however from Watson et al. (1997), who pointed out that AA is not as popular in Canada or England as it is in America. They did not, however, provide any data to collaborate this and it should be noted that it would be hard to find rates of approval as high as those quoted for the USA.

Chappel (1992) maintains that the three major components of AA are meetings, the fellowship and step-work. AA meetings can take different forms, focusing on the 12 steps (Alcoholics Anonymous 1952), the Big Book (Alcoholics Anonymous 1976) or on individual speakers or themes. They are classified as either open (where any interested party can attend) or closed (only for those who have a desire to stop drinking). Fellowship is characterized by Chappel (1992) as a sense of communion with other alcoholics, including being accepted and understood, developing friendly relationships, acquiring a sponsor and involvement in a kind of extended family. Step-work involves working through the 12 steps (see Figure 1) and employing them in daily life. This is conducted both during AA meetings and during informal gatherings of AA members. Both Miller and Mahler (1991) and Chappel (1992) provide an outline of the processes and activities involved in working each step. There is some evidence to say that AA differs across countries (e.g. Mäkelä“ 1993; Mäkelä et al. 1996). However, England has not been included in these comparisons and therefore the extent of the differences and similarities are unknown. Nevertheless, the formal activities and literature of AA are uniform at least across all English-speaking countries.

The search for the characteristics of treatment centre clients most likely to succeed in AA, and indeed the evaluation of AA as a treatment and recovery resource, has been hampered by a number of factors, including difficulties in gaining access and in implementing appropriate research designs (Kassel and Wagner 1993, McKay and Maisto 1993, Tonigan et al. 1996b). Aside from self reported membership, meeting attendance has been the most frequently invoked measure of affiliation in the literature (Emrick et al. 1993). The appropriateness of using meeting attendance is based directly on AA literature. As Khantzian and Mack (1994) observed, one of the AA slogans is 'more meetings, more sobriety; less meetings, less sobriety; no meetings, no sobriety'. Nevertheless, there have also been increasing calls for more sophisticated methods of measuring membership and affiliation. These have included both Emrick et al. (1993) and Tonigan et al. (1996a) who noted that while most studies measured AA affiliation in terms of frequency of attendance, others have included such components as increasing participation, having or being a sponsor, leading meetings, sharing at meetings, doing 12th-step-work and the extent of working particular AA steps.

The literature in the area of measuring involvement with AA has developed considerably in recent years. Numerous authors have discussed and recommended methods for assessing affiliation with AA in sophisticated ways. A 'Steps Questionnaire' has been designed to 
assess how members feel they have covered steps 1-3 of AA see Figure 1; Gilbert 1991). Similarly, a measure to assess the processes involved in working the 12 steps was introduced by Montgomery et al. (1995). A measure of involvement which incorporates the number of friends that are active in AA, perceived importance of AA to recovery and the degree to which participants' lives revolve around AA-oriented activities has also been developed (Snow et al. 1994). Tonigan et al. (1996a) reported on the AA Involvement Scale (AAI) that incorporates perceived commitment to AA and the degree to which members worked the 12 steps. A separate 12-step commitment measure was introduced by Kingree and Ruback (1994), comprising nine items all drawn from the organizational psychology literature.

Figure 1 The Twelve Steps of Alcoholics Anonymous

1. We admitted we were powerless over alcohol - that our lives had become unmanageable.

2. Came to believe that a power greater than ourselves could restore us to sanity.

3. Made a decision to turn our will and our lives over to the care of God as we understood Him

4. Made a searching and fearless moral inventory of ourselves.

5. Admitted to God, to ourselves and to another human being the exact nature of our wrongs.

6. Were entirely ready to have God remove all these defects of character

7. Humbly asked him to remove our shortcomings

8. Made a list of al persons we had harmed, and became willing to make amends to them all.

9. Made direct amends to such people wherever possible, except when to do so would injure them or others.

10. Continued to take personal inventory and when we were wrong promptly admitted it.

11. Sought through prayer and meditation to improve our conscious contact with God as we understood him, praying only for knowledge of his will for us and the power to carry that out.

12. Having had a spiritual awakening as the result of these steps, we tried to carry this message to alcoholics and to practice these principles in al our affairs.

However, it should also be noted that the introduction of these measures has not revolutionized the field (Allen 2000). Although Montgomery et al. (1995) found that drinking outcomes were predicted by their General AA Tools of Recovery (GAATOR) (r 20.44), low to modest relationships between step working (step 1, r 0.26; step 2, r 0.16) and drinking outcomes have also been reported (Gilbert 1991). The differences in outcome identified by Snow et al. (1994) varied little according to how AA membership was measured (exposure, frequency of attendance or involvement as mentioned above). Although Tonigan and HillerSturmho" fel (1994) did recommend that further work employ these sorts of more sophisticated measures, and numerous relevant hypotheses were suggested by Allen (2000), no consensus yet exists on the way forward.

While authors continue to debate these issues, it is unknown how appropriate they are perceived to be by members themselves, or indeed how relevant they are to AA members in England. This study aims to redress this by providing data on aspects of AA membership in England and how these are related to sociodemographic characteristics of members.

Specifically, this study aims to document the perceptions that AA members have of the nature of success within AA and whether these perceptions are associated with other parameters of membership.

\section{METHODS}

This study is a cross-sectional survey of AA members living in the community. The General Service Office of Alcoholics Anonymous (UK) provided the addresses of 56 AA meetings in 
the East Midlands region of England. Letters were written blind to 'the secretary' of each group who was requested to ask attendees if they would like to participate. Twenty-five copies of the questionnaire, along with individual explanatory letters and stamped addressed envelopes to facilitate return, were sent to each of the 13 meeting secretaries who expressed an interest in this study.

Respondents were asked to return a self-completion questionnaire, which contained both closed and open questions. These included questions designed to assess both perceived and attained success with AA. Respondents were asked how long they had been attending meetings, when they had first attended, if they had been attending regularly since then, when they last had an alcoholic drink and whether they had been attending regularly since then. In addition, respondents were asked to report their frequency of meeting attendance. There were two questions in relation to this, the first asked about what they considered 'regular attendance' to be and the second asked how frequently they themselves attended meetings. Involvement in 12-stepping, a central AA activity integral to the notion of 'service' was also considered appropriate measure of membership. This stems from the twelfth of the 12 steps (see Figure 1) and involves meeting with people who have a desire to stop drinking and who have asked for help from AA as well as sponsoring new members (Nowinski 1993). Typically a 12-step visit involves same-sex AA members visiting the person who has asked for help and telling their personal 'stories', what their lives were like when they were drinking, how they found AA and what their lives are like now. Sponsoring involves being available for new members, and showing them how to work the 12 steps. Respondents were asked to rate on a seven-point Likert-type scale how comfortable they felt about 12-stepping and how eager they felt to 12-step again.

In addition to this, respondents were asked to say in their own words what they thought it meant to be a successful AA member. These responses were analysed according to the principles outlined by Feldman (1995) and the resulting constructed categories (drinking behaviour / sobriety, service to others, meeting attendance, the 12 steps, sharing / honesty) were data driven. Responses from each participant were then coded for the presence or absence of these categories. Those codings were correlated with codings completed 2 weeks later with rphi 0.91. Thus, there is a set of self-reported behavioural measures which could be used as a proxy for success, and there are open-ended data collected which investigate participants perceptions of success. Sociodemographic differences (age, gender, marital status, being a parent, occupational group) Perceptions of sobriety are explored across response categories and these are reported below. Finally, the relationships between these measures of 'success' are presented. Data have been analysed with students' $t$ tests, chi square and Fischer's exact probability, as appropriate.

\section{RESULTS}

Seventy-seven questionnaires were returned (75 completed fully) from a total of nine different AA groups. Of those that responded, $50(65 \%)$ were male and the mean age was 45.4 years (SD 10.8). Respondents reported a mean of 12.7 (SD 3.1) years of full-time education and their modal social class was II (lower professional and white collar). Most (57\%) were currently married and the mean number of reported children was 1.9 (SD 1.4). The average participant had been attending AA meetings for $8 \mathrm{~K}$ years and last had an alcoholic drink just over 5 years ago. They reported attending two AA meetings per week and considered themselves to be both regular attendees and successful members of AA.

\section{Parameters of membership}

All membership variables were assessed for distribution and the resultant descriptive statistics are presented in Table 1. All variables were significantly skewed and thus were dichotomized. In relation to length of membership, 12 months was chosen as the dichotomy point, because in AA, new members are advised not to make any life-changing decisions for at least 1 year. Twenty four (30\%) of those surveyed said that they had not been regular attendees since their 
first contact, and most of these had returned to drinking for some time. All of those who responded said that they had been regular attendees since their last drink or 'slip'. Length of time since last drink was also dichotomized at 1 year. Perceived regular attendance was dichotomized on the basis of whether respondents reported attending more or less frequently than they themselves considered regular. Comfortableness with and eagerness to 12-step were dichotomized at or just below the median.

All these dichotomized membership variables were compared with the sociodemographic variables and only age differed significantly according to eagerness to 12-step (pv0.05). Those who were more eager to 12-step were significantly older (mean age 47.4 , SD 11) than those who were less eager (mean age 41.7, SD 8.4).

\section{Perceived meaning of success}

The most common response to this open-ended question was a comment on drinking behaviour or sobriety which 50 out of 77 members mentioned; however, these comments fell into three distinct categories.

1 Those who mentioned 'one day at a time' - ODAAT (n 17)

. 'To be sober today'

. 'To stay away from that first drink, one day at time'

. 'First and foremost to stay sober one day at a time'

2 Those who mentioned long-term or continued sobriety $(\mathrm{n} \sim 17)$

. 'To maintain abstinence from alcohol'

. 'To stay sober'

. 'To stay sober forever'

3 Those who mentioned quality of sobriety ( $\mathrm{n} 16)$

. 'Be at peace with yourself'

- 'To be sober, sincere, communicative, caring, honest, willing to learn, feeling part of the 12step family'

. 'Achieving serenity'

These appear to be quite different sides to non-drinking, stemming from different aspects of AA philosophy. Those who mentioned quality sobriety or continued sobriety were considered to be more stable members. Those who mentioned ODAAT, which is a common AA slogan, had at least adopted some of the terminology of the organization. Other responses are presented here in order of frequency of appearance;

4 Being of service to others (12-stepping, etc.) (n 22)

. 'carrying the message to still suffering alcoholics'

5 Attending meeting regularly $(\mathrm{n} \sim 14)$

. 'regular attendance at meetings'

6 following the programme and/or the 12 steps (n 13)

. 'working the 12 steps'

7 Sharing honestly (n 13)

. 'complete honesty with yourself and other members'

The presence or absence of responses in any of these categories was analysed in conjunction with all the sociodemographic factors. Two significant differences emerged. Single respondents were more likely to mention ODAAT compared with those who were co-habiting or married (pv0.05). Those who mentioned service to others reported significantly shorter lengths of marital status, regardless of status, (mean 12.1, SD 10.8) compared with those who did not mention service (mean 19.1, SD 10.7, p<0.05). 
Table 1 Membership variables; descriptive statistics

\begin{tabular}{|c|c|c|c|c|c|}
\hline Variable & $\mathrm{n}$ & Mean (SD) & Median & Skew & Dichotomy point \\
\hline Length of membership & 75 & $\begin{array}{l}87(90.9) \\
\text { months }\end{array}$ & 51 months & $\mathrm{P}<0.001$ & $\begin{array}{l}12 \text { months ( } \leq 12 \mathrm{~m} ; 12 \%:>12 \\
\mathrm{~m} ; 88 \%)\end{array}$ \\
\hline $\begin{array}{l}\text { Time since last } \\
\text { alcoholic drink }\end{array}$ & 75 & $\begin{array}{l}59.3(75.1) \\
\text { months }\end{array}$ & 30 months & $\mathrm{P}<0.001$ & $\begin{array}{l}12 \text { months ( } \leq 12 \mathrm{~m} ; 29 \%:>12 \\
\mathrm{~m} ; 71 \%)\end{array}$ \\
\hline $\begin{array}{l}\text { Reported meeting } \\
\text { attendance }\end{array}$ & 75 & $\begin{array}{l}9.6(5.5) \text { per } \\
\text { month }\end{array}$ & 8 per month & $\mathrm{P}<0.001$ & $\begin{array}{l}8 \text { per month }(<8 ; 55 \% \text { : } \geq 8 \text {; } \\
45 \%)\end{array}$ \\
\hline $\begin{array}{l}\text { Perceived regular } \\
\text { attendance }\end{array}$ & 70 & $\begin{array}{l}7.9(5.4) \text { per } \\
\text { month }\end{array}$ & 4 per month & $\mathrm{P}<0.001$ & $\begin{array}{l}\text { Regular attendance (>regular; } \\
49 \%: \leq \text { regular; } 51 \% \text { ) }\end{array}$ \\
\hline $\begin{array}{l}\text { Comfortable with } 12- \\
\text { stepping }\end{array}$ & 54 & $5.1(1.2)$ & 5 & $\mathrm{P}<0.01$ & $\begin{array}{l}\text { Comfortable rating }(1-5 ; 51 \% \text {; } \\
6-7 ; 49 \%)\end{array}$ \\
\hline Eagerness to 12 -step & 54 & $5.6(2.2)$ & 7 & $\mathrm{P}<0.001$ & $\begin{array}{l}\text { Eagerness rating (1-6; 41\%: } 7 \text {; } \\
(59 \%)\end{array}$ \\
\hline
\end{tabular}

\section{Relationships between measures of AA membership}

Chi square tests were conducted between all the dichotomized membership measures discussed above. A number of these reached statistical significance, but most proved unsurprising. Comfortableness with, and eagerness to 12 -step were significantly related (pv0.001); those who were more comfortable were likely to be more eager. In addition, length of time since last drink was significantly related to length of AA membership (pv0.001).

The qualitative categories of meaning of success also showed some associations with the selfreported behavioural measures. Those who mentioned OOADT were less likely to be attending more meetings than they themselves considered regular attendance (pv0.05). Those who said that service to others was important were less likely to have reported feeling comfortable with 12- stepping (pv0.01). There were also two significant relationships identified within the qualitative categories. Having said OOADT was significantly different from having said 'quality sobriety' (pv0.01), in fact, no single respondent said both. Similarly, it was significantly different from having mentioned 'long term sobriety' (pv0.01) where no single respondent mentioned both concepts.

\section{DISCUSSION}

This study provides the first picture of AA membership in the UK since 1979 (Robinson 1979). It is impossible to calculate response rates for a number of reasons. It is unknown how many of the initial letters actually reached meeting secretaries; meeting addresses, and days and times change regularly. Although 25 questionnaires were sent to each meeting address, it is impossible to know how many regular attendees or members associated with any one meeting or how many questionnaires were actually distributed. Because of the fluidity of the organization, a number of the groups contacted may no longer be in existence or may have moved to a different meeting place. Owing to overlap in meeting attendance (members attending a number of different meetings each week), any member could have received two or even more questionnaires from different secretaries. There is no 'organizational' time routinely set aside at AA meetings and, therefore, no obvious time during which secretaries could raise the issue. Some secretaries announced the existence of the project at a meeting and others reportedly approached members individually. The apparent low response rate may be compensated for somewhat by the motivation of those responding, which may indeed add to the validity of the data. Nevertheless, care should be taken not to over-generalize nor to over-interpret these data based on the possible differences across countries in AA practices identified by Maäkelä et al. (1996) and the unknown representativeness of the current data.

Although the data reported here are based on self-reports and subject to self-selection bias, the sociodemographic characteristics of respondents are themselves of considerable interest. The sociodemographic characteristics of the current sample can be compared to those presented by Emener and Dickman (1992) from their survey of the characteristics of AA members in 
Tampa Bay, the data presented by Emrick et al. (1993) from their meta-analyses of AA research reports, and the most recent report of AA membership in Great Britain (Alcoholics Anonymous 1991).

The age of the current sample is comparable to the mean age reported by Emrick et al. (1993) of 42 years and that reported by Emener and Dickman (1992) of 41 years. They are also similar to the data presented by Alcoholics Anonymous (1991), which reported a modal age class of $41-50$ years $(35 \%)$. In relation to gender, although women comprise $30 \%$ of membership in the USA (Alcoholics Anonymous 1990) and 36\% of membership in Great Britain (Alcoholics Anonymous 1991), they have been underrepresented in research on AA (Emrick et al. 1993, Miller and McCrady 1993). At 35\%, the current sample contains a more representative gender balance.

In relation to length of membership in AA and length of sobriety, the current AA sample appears similar to that reported by Alcoholics Anonymous (1993). In the current sample, 12\% had their first contact with AA within the last 12 months; the corresponding national figure was $16 \%$. The median number of months of contact was 51 (4.25 years) compared with the modal class of length of contact reported by Alcoholics Anonymous (1991) which was 2-6 years $(29 \%)$. Twenty-nine per cent of the current sample had had an alcoholic drink within the previous 12 months, and the corresponding figure for the national sample was also $29 \%$. The median length since last drink for the current sample was 30 months ( 2.5 years), while the corresponding modal class for the national study was 2-10 years.

The assessment of successful AA membership is one of the most challenging aspects of work in this field. Although abstinence itself is clearly the most obvious marker of success, it is not sufficiently sensitive. As a consequence, longevity of membership, length of sobriety, frequency of meeting attendance and twelve-stepping were included to help assess successful membership. In addition, participants were asked about what they thought Perceptions of sobriety it meant to be a successful AA member. It is considered that employing these as markers of success in AA contributes a strength that provides a variety of perspectives on AA, and facilitates the identification of factors that influence success across such perspectives.

The overlap between responses to the open question on the perceived meaning of success and some of the behavioural measures is worthy of note. The employment of meeting attendance, service to others, sobriety and working the programme have therefore acquired some face validity and should be considered as appropriate markers of successful membership. Although the membership variables that would be expected to be related to one another have illustrated significant associations here (e.g. eagerness and comfortableness with 12-stepping), other analyses indicate the lack of association between what participants think is success and their own behaviour (e.g. meeting attendance). This illustrates the difference between perceptions of success and self-reported behaviour; related, but distinct aspects of membership.

\section{CONCLUSION}

The strength of these findings lies within their context. The respondents are community-based self-identified members of AA whose characteristics do not differ significantly from those of members reported by AA itself, but which represent a more gender appropriate balance than previous AA samples. The finding that AA members volunteered as aspects of 'success' very similar variables as have been previously mentioned in the literature and as have been measured separately here, affords some confidence in their use. The overall dearth of sociodemographic differences in response to these questions also strengthens their case for inclusion in future research. The lack of a general association at an individual level between perceived success and self-reported behaviours suggest that respondents were not merely reporting their own behaviours as evidence of success. These measures are simple to employ and illustrate no demographic bias. While it would be appropriate to explore in more detail 
their relationships with the measures of involvement discussed above, it is also appropriate to consider how these aspects of membership may be facilitated within primary treatment facilities.

\section{ACKNOWLEDGEMENTS}

I acknowledge the support of the Alcohol Education and Research Council and Professor Tom Cox formerly of the Department of Psychology, University of Nottingham during the course of this work.

\section{REFERENCES}

AA (2002) http://www.alcoholics-anonymous.org (15 October 2002). Alcoholics Anonymous (1952) Twelve Steps and Twelve Traditions. AA World Services, Inc.: New York.

Alcoholics Anonymous (1976) Alcoholics Anonymous: The Story of How Many Thousands of Men and Women Have Recovered from Alcoholism. AA World Services Inc.: New York.

Alcoholics Anonymous (1991) Survey of Alcoholics Anonymous in Great Britain. AA General Service Board Great Britain: York.

Alcoholics Anonymous (1993) Alcoholics Anonymous. AA World Services, Inc.: New York. Allen JP (2000) Measuring treatment process variables in Alcoholics Anonymous. Journal of Substance Abuse Treatment 18 (3): 227-30.

Chappel JN (1992) Effective use of Alcoholics Anonymous and Narcotics Anonymous in treating patients. Psychiatric Annals 22 (8): 409-18.

Clark WH (1951) The Oxford Group. Buchman Associates: New York.

Davidson R (2002) The Oxford Group and Alcoholics Anonymous. Journal of Substance Use 7 (1): 3-5.

Emener WG and Dickman JF (1992) Significant demographic characteristics of persons recovering from alcoholism and other drugs. Journal of Applied Rehabilitation Counselling 23 (1): 3-17.

Emrick C (1989) Alcoholics Anonymous: emerging concepts. In: Galanter M (ed.) Recent Developments in Alcoholism (vol. 7). Plenum: New York, pp. 37-53.

Emrick CD, Tonigan JS, Montgomery H and Little L (1993) Alcoholics Anonymous: what is currently known. In: McCrady BS,

Miller WR (eds) Research on Alcoholics Anonymous: Opportunities and Alternatives. Rutgers Center of Alcohol Studies: New Jersey, pp. 41-76.

Feldman MS (1995) Strategies for Interpreting Qualitative Data. Sage: Thousand Oaks, CA.

Galaif ER and Sussman S (1995) For whom does Alcoholics Anonymous work? International Journal of the Addictions 30 (2): 161-84.

Gilbert FS (1991) Development of a 'Steps Questionnaire'. Journal of Studies on Alcohol 52 (4): 353-30.

Hasin DS and Grant BF (1995) AA and other helpseeking for alcohol problems: former drinkers in the US general population. Journal of Substance Abuse 7 (3): 281-92.

Humphreys K (1997) Clinicians' referral and matching of substance abuse patients to selfhelp groups after treatment. Psychiatric Services 48 (11): 1445-9.

Kassel JD and Wagner EF (1993) Processes of change in Alcoholics Anonymous: a review of possible mechanisms. Psychotherapy 30 (2): 222-34.

Khantzian EJ and Mack JE (1989) Alcoholics Anonymous and contemporary psychodynamic treatment. In: Galanter M (ed.) Recent Developments in Alcoholism (vol. 7). Plenum: New York, pp. 67-89.

Kingree JB and Ruback R (1994) Understanding self-help groups. In: Powell TJ (ed.) Understanding the Self-help Organisation: Frameworks and Findings. Sage: Thousand Oaks, CA, pp. 272-292.

Kurtz LF (1984) Ideological differences between professionals and AA members. Alcoholism Treatment Quarterly 1 (2): 73-85.

McKay JR and Maisto SA (1993) An overview and critique of advances in the treatment of alcohol use disorders. Drugs and Society 8 (1): 1-29. 
Mäkelä K (1993) Implications for research of the cultural variability of Alcoholics Anonymous. In: McCrady BS, Miller WR (eds) Research on Alcoholics Anonymous: Opportunities and Alternatives. Rutgers Center of Alcohol Studies: New Jersey, pp. 189208.

Mäkelä K, Arminen I, Bloomfield K, Eisenbach-Stangl I, Bergmark KH, Kurube N, Mariolini N, Olafsdottir H, Peterson JH, Phillips M, Rehm J, Room R, Rosenqvist P, Rosovksy H, Stenius K, Swiatkiewicz G, Woronowicz B and Zielinski A (1996) Alcoholics

Anonymous as a Mutual Help Movement: A Study in Eight Societies.University of Wisconsin Press: Madison, WI.

Miller NS and Mahler JC (1991) Alcoholics Anonymous and the 'AA' model for treatment. Alcoholism Treatment Quarterly 8 (1): 39-51.

Miller NS, Gold MS and Smith DE (eds)(1997) Manual of Therapeutics for Addictions. Wiley: New York.

Miller WR and McCrady BS (1993) The importance of research on Alcoholics Anonymous. In: McCrady BS, Miller WR (eds) Research on Alcoholics Anonymous: Opportunities and Alternatives Rutgers Center of Alcohol Studies: New Jersey, pp. 1-12.

Montgomery HA, Miller WR and Tonigan JS (1995) Does Alcoholics Anonymous involvement predict treatment outcome? Journal of Substance Abuse Treatment 12 (4): 241-6.

Nowinski J (1993) Questioning the answers: research and the AA traditions. In: McCrady BS, Miller WR (eds) Research on Alcoholics Anonymous: Opportunities and Alternatives. Rutgers Center of Alcohol Studies: New Jersey, pp. 27-39.

Robinson D (1979) Talking out of Alcoholism. Croom Helm: London. Snow MG, Prochaska JO and Rossi JS (1994) Processes of change in Alcoholics Anonymous: maintenance factors in long term sobriety. Journal of Studies on Alcohol 55 (3): 362-71.

Tonigan JS and Hiller-Sturmho" fel S (1994) Alcoholics Anonymous: who benefits? Alcohol, Health and Research World 18 (4): 308-10.

Tonigan JS, Connors GJ and Miller WR (1996a) Alcoholics Anonymous Involvement (AAI) Scale: reliability and norms. Psychology of Addictive Behaviours 10 (2): 75-80.

Tonigan JS, Toscova R and Miller WR (1996b) Meta-analysis of the literature on Alcoholics Anonymous: sample and study characteristics moderate findings. Journal of Studies on Alcohol 57 (1): 65-72.

Velleman R and Orford J (1990) Young adult offspring of parents with drinking problems: Recollections of parents' drinking and its immediate effects. British Journal of Clinical Psychology 29 (3): 297-317.

Watson CG, Hancock M, Gearhart LP, Mendez CM, Malovrh P and Raden M (1997) A comparative study of frequent, moderate, occasional and nonattenders of Alcoholics Anonymous. Journal of Clinical Psychology 53 (3): 209-14.

Weisner C, Greenfield T and Room R (1995) Trends in the treatment of alcohol problems in the US general population, 1979 through 1990. American Journal of Public Health 85 (1): $55-60$.

WW (1949) The society of Alcoholics Anonymous. American Journal of Psychiatry 106: 370-6.

Zweben JE, Smith DE and Buxton ME (1987) Editor's introduction. Journal of Psychoactive Drugs 19 (3): 227-9. 